Article

\title{
Deposition of NiO Nanoparticles on Nanosized Zeolite NaY for Production of Biofuel via Hydrogen-Free Deoxygenation
}

\author{
Min-Yee Choo ${ }^{1,2,3}$, Lee Eng Oi ${ }^{1}$, T. Jean Daou ${ }^{4} \mathbb{D}$, Tau Chuan Ling ${ }^{2}$, Yu-Chuan Lin ${ }^{5}{ }^{\mathbb{D}}$, \\ Gabriele Centi ${ }^{6}$, Eng-Poh $\mathrm{Ng}^{3, *(D)}$ and Joon Ching Juan ${ }^{1,7, *}$ \\ 1 Nanotechnology and Catalysis Research Center (NANOCAT), University of Malaya, \\ Kuala Lumpur 50603, Malaysia; alexandriachoo@gmail.com (M.-Y.C.); oi.leann@gmail.com (L.E.O.) \\ 2 Institute of Biological Sciences, Faculty of Science, University of Malaya, Kuala Lumpur 50603, Malaysia; \\ tcling@um.edu.my \\ 3 School of Chemical Sciences, Universiti Sains Malaysia (USM), Penang 11800, Malaysia \\ 4 Institut de Science de Matériaux de Mulhouse UMR, Université de Haute-Alsace, Université de Strasbourg, \\ Axe Matériaux à Porosités Contrôlées, 7361, ENSCMu, 3b rue Alfred Werner, 68093 Mulhouse, France; \\ jean.daou@uha.fr \\ 5 Department of Chemical Engineering, National Cheng Kung University, No. 1 University Road, \\ Tainan 70101, Taiwan; yclin768@mail.ncku.edu.tw \\ 6 Departments ChiBioFarAm and MIFT, ERIC aisbl and CASPE/INSTM, University of Messina, viale F. Stagno \\ d'Alcontres 31, 98166 Messina, Italy; centi@unime.it \\ 7 Sunway Campus, Monash University, Jalan Lagoon Selatan, Bandar Sunway 46150, Selangor, Malaysia \\ * Correspondence: epng@usm.my (E.-P.N.); jcjuan@um.edu.my (J.C.J.)
}

Received: 22 June 2020; Accepted: 9 July 2020; Published: 11 July 2020

check for updates

\begin{abstract}
Nickel-based catalysts play an important role in the hydrogen-free deoxygenation for the production of biofuel. The yield and quality of the biofuel are critically affected by the physicochemical properties of $\mathrm{NiO}$ supported on nanosized zeolite Y (Y65, crystal size of $65 \mathrm{~nm})$. Therefore, $10 \mathrm{wt} \%$ $\mathrm{NiO}$ supported on $\mathrm{Y} 65$ synthesized by using impregnation (IM) and deposition-precipitation (DP) methods were investigated. It was found that preparation methods have a significant effect on the deoxygenation of triolein. The initial rate of the DP method $\left(14.8 \mathrm{~g}_{\mathrm{oil}} \cdot \mathrm{h}^{-1}\right)$ was 1.5 times higher than that of the IM method $\left(9.6 \mathrm{~g}_{\mathrm{oil}} \cdot \mathrm{h}^{-1}\right)$. The DP-Y 65 showed the best deoxygenation performance with a $80.0 \%$ conversion and a diesel selectivity of $93.7 \%$ at $380{ }^{\circ} \mathrm{C}$ within $1 \mathrm{~h}$. The outstanding performance from the DP method was due to the smaller NiO particle size $(3.57 \pm 0.40 \mathrm{~nm})$, high accessibility (H.F value of 0.084 ), and a higher Brönsted to Lewis acidity $(\mathrm{B} / \mathrm{L})$ ratio $(0.29)$, which has improved the accessibility and deoxygenation ability of the catalyst. The $\mathrm{NH}_{4}{ }^{+}$released from the decomposition of the urea during the DP process increased the $\mathrm{B} / \mathrm{L}$ ratio of zeolite $\mathrm{NaY}$. As a result, the pretreatment to convert Na-zeolite to H-zeolite in a conventional zeolite synthesis can be avoided. In this regard, the DP method offers a one-pot synthesis to produce smaller NiO-supported nanosized zeolite $\mathrm{NaY}$ with a high $\mathrm{B} / \mathrm{L}$ ratio, and it managed to produce a higher yield with selectivity towards green diesel via deoxygenation under a hydrogen-free condition.
\end{abstract}

Keywords: $\mathrm{NiO}$; zeolite Y; deposition-precipitation; triolein; green diesel

\section{Introduction}

Currently, fossil fuels (coal, petroleum, and natural gas) are the main energy sources that supply our energy demand. According to the International Energy Agency (IEA), fossil fuels have contributed to nearly $70 \%$ of the global primary energy demand where transportation has accounted for $25.8 \%$ of 
the energy used from fossil fuels [1,2]. Burning fossil fuel leads to global warming due to the emission of greenhouse gases (GHG) such as $\mathrm{CO}_{2}$ [3]. The ability of the oil crops to utilize the $\mathrm{CO}_{2}$ through photosynthesis has made biofuel a carbon neutral fuel [4]. Therefore, biofuel, which is environmentally friendly, renewable, and sustainable, is a promising alternative to substitute fossil fuel [5].

There are different types of feedstock for biofuel production. For example, the first-generation feedstock uses edible oil crops such as palm, soybean and sunflower [6,7]. However, the low productivity and requirement of arable land have received some debates in the scientific community. In the second-generation biofuel feedstock, waste feedstocks such as waste cooking oil and lignocellulosic feedstocks are used, and they are better than the first-generation feedstock in terms of the impact to the environment. However, their supplies to fulfil the large biofuel market is a real challenge [8]. Microalgae has emerged as a third-generation feedstock due to its simple growth requirement and high biomass growth. However, high biomass growth is often accompanied with low oil productivity and vice versa [9]. Therefore, engineered microalgae is considered as the fourth-generation feedstock due to its high $\mathrm{CO}_{2}$ sequestration ability, high growth, and lipid productivity [5].

In biofuel production, biodiesel or fatty acid methyl ester (FAME) is derived from the transesterification of triglyceride in oil crops, such as microalgae, soybean, rapeseed, and palm oil, which have been extensively studied $[6,10,11]$. However, the oxygen content, fluid density, flash point, and viscosity of biodiesel in a high extent have limited its direct application in transportation $[12,13]$. Hence, it is often blended with petroleum diesel with a low blending ratio $(<20 \%)$ [12]. As a result, biofuel such as biodiesel only contributes to about $5 \%$ of the energy source in the U.S. transportation sector [2]. In order to improve the biofuel quality, the elimination of oxygen atoms from the biofuel is needed so that its performance is comparable with the petroleum-based fuel. Deoxygenation is a promising thermochemical process that enables the removal of oxygenated compounds present in the biofuels. In general, deoxygenation proceeds through two major routes, namely (a) hydrodeoxygenation (HDO) and (b) decarbonylation and decarboxylation (DCO). HDO is a highly efficient process in removing oxygenated compounds but it requires high hydrogen $\left(\mathrm{H}_{2}\right)$ pressure during the process [14]. This becomes a major drawback of the HDO process as the hydrogen gas is mainly derived from the fossil fuels in the current stage [15]. Hence, the production of renewable biofuel from triglycerides without using an external hydrogen source is interesting. For example, DCO reactions using inexpensive solid acid or base catalysts to produce hydrocarbon-like biofuel under $\mathrm{H}_{2}$-free condition are reported [16-18]. Oi et al. reported that $76.9 \%$ of triolein conversions with $32.0 \%$ DCO selectivity have been attained

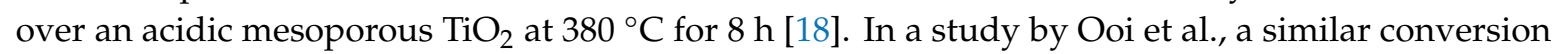
$(76.9 \%)$ was attained with shorter reaction time $(4 \mathrm{~h})$ over $0.2 \mathrm{Ti}-0.8 \mathrm{Al}$ mixed oxide but with a lower DCO selectivity (27.3\%) [17]. The performance of the deoxygenation catalysts can be improved by adding active metal species. Metal-supported catalysts with noble metals $(\mathrm{Pd}, \mathrm{Ru}, \mathrm{Pt})$ and transition metals ( $\mathrm{Ni}, \mathrm{Fe}, \mathrm{Cu}, \mathrm{Co}$ ), have been reported in the deoxygenation reaction [19-23]. However, noble metals are very expensive with limited resources. Therefore, transition metals with a high abundancy and low cost seem to be a better choice as deoxygenation catalysts.

Among the commonly used transition metals $(\mathrm{Ni}, \mathrm{Fe}, \mathrm{Cu}, \mathrm{Co}), \mathrm{Ni}$ is widely studied in deoxygenation due to its high hydrogenolysis ability [24-26]. Besides the selection of active metals, the metal preparation method could affect the physicochemical properties and the reactivity as well $[27,28]$. There are many synthesis methods in preparing metal-supported catalysts such as impregnation, ion-exchange, sol-gel, and deposition-precipitation. However, each method has its strength and weakness. For instance, the sol-gel (SG) method is capable of achieving good metal dispersion, but it is not suitable for high metal loading as the particles tend to agglomerate into large particles [29]. Meanwhile, ion-exchange (IE) method is also capable of achieving good metal dispersion, but it is limited to the exchange ability of the support. Furthermore, multiple ion-exchange is often needed to achieve high metal loading [30]. On the other hand, despite large metal particle sizes being often produced, the impregnation (IM) method is widely used due to its simplicity, and it is able to achieve high metal loading [31]. Deposition-precipitation (DP) is well known for producing 
small-sized metal particles [27]. This method involves the precipitation of metal in the form of metal hydroxide followed by deposition on the catalyst. Unlike the previous two methods, the DP method is suitable in preparing metal-supported catalysts with higher metal loadings $(\sim 40 \%)$ [32]. The variation in the preparation method will lead to different physicochemical properties and lead to a different catalytic performance. For instance, the size of Ni nanoparticles supported on zeolite Beta (H-BEA) has demonstrated a significant difference in the HDO of microalgae oil, where small Ni nanoparticles (particle size $\sim 3.9 \mathrm{~nm}$ ) prepared using the DP method exhibit a higher reactivity and faster initial rate than Ni particles prepared using the IM method (particle size $24.7 \mathrm{~nm}$ ) [27]. However, metallic Ni requires prereduction in a hydrogen atmosphere and is prone to oxidation during treatment. Therefore, metallic metal is not suitable for the $\mathrm{H}_{2}$-free reaction environment.

In recent studies, transition metals in oxide form (TMO) have received much interest in hydrogen-free deoxygenation because they do not require a prereduction step [33,34]. In our previous contribution, we tested the deoxygenation ability of various $\mathrm{TMOs}(\mathrm{Ni}, \mathrm{Cu}, \mathrm{Co}, \mathrm{Mn}$, and $\mathrm{Zn}$ ) impregnated on commercial micron-sized zeolite $\mathrm{Y}$ in the hydrogen-free deoxygenation of triolein. Among these TMOs, nickel oxide (NiO) showed the best deoxygenation performance [26]. Similarly, the enhancement of the deoxygenation of vegetable oil were also reported for $\mathrm{NiO}$ impregnated on hexagonal mesoporous silica (HMS) and aluminum-Santa Barbara Amorphous type material number 15 (Al-SBA-15) [35,36]. However, there is a lack of studies on the effect of $\mathrm{NiO}$ particle size towards deoxygenation of nonedible oil. Furthermore, although the DP method has been extensively studied with $\mathrm{H}$ - or $\mathrm{NH}_{4}$-form zeolite [31,37], the effect of this method in the physicochemical properties such as acidity on Na-form zeolite remains unknown. In conventional zeolite $\mathrm{Y}$ synthesis, an $\mathrm{H}$-form zeolite is prepared by the ion-exchange of Na-form zeolite with $\mathrm{NH}_{4}{ }^{+}$and followed by calcination [38]. Therefore, the $\mathrm{NH}_{4}{ }^{+}$released through the decomposition of urea may serve as the ion-exchange agent, and a two-step calcination can be avoided.

Previously, we reported that the nanosized zeolite NaY could improve the deoxygenation performance of triolein in the absence of a hydrogen source [39]. In this study, we extend the utilization of nanosized zeolite $\mathrm{NaY}$ by loading with $\mathrm{NiO}$ nanoparticles prepared using different synthesis methods. Due to the high metal content $(10 \mathrm{wt} \% \mathrm{Ni}$ ) being used in this study, impregnation (IM) and deposition-precipitation (DP) methods are selected for the investigation. Their physicochemical properties and performances in the $\mathrm{H}_{2}$-free deoxygenation of triolein are also discussed.

\section{Experimental Section}

\subsection{Synthesis of Parent Nanosized Zeolite NaY with Crystal Size of $65 \mathrm{~nm}(\mathrm{Y} 65)$}

The parent Y65 was synthesized according to our previous work [39]. Briefly, solution A was prepared by dissolving $\mathrm{NaOH}$ (1.500 g, 99\%, Merck, Darmstadt, Germany) and sodium aluminate (2.693 g, 53.0\% $\mathrm{Al}_{2} \mathrm{O}_{3}, 42.5 \% \mathrm{Na}_{2} \mathrm{O}$, Sigma-Aldrich, Malaysia) in distilled water (13.000 g). Solution $\mathrm{B}$ was prepared by mixing sodium silicate $\left(45.343 \mathrm{~g}, 26.5 \% \mathrm{SiO}_{2}, 10 \% \mathrm{Na}_{2} \mathrm{O}\right.$, Sigma-Aldrich, Darmstadt, Germany) with $\mathrm{NaOH}(3.671 \mathrm{~g})$ and distilled water (16.079 g). Solution A was added dropwise to solution $\mathrm{B}$ under vigorous stirring in an ice bath. The resulting clear suspension with a molar composition of $8 \mathrm{Na}_{2} \mathrm{O}: 0.7 \mathrm{Al}_{2} \mathrm{O}_{3}: 10 \mathrm{SiO}_{2}: 160 \mathrm{H}_{2} \mathrm{O}$ was aged $\left(25^{\circ} \mathrm{C}, 24 \mathrm{~h}\right)$ before being subjected to crystallization $\left(120^{\circ} \mathrm{C}, 70 \mathrm{~min}\right)$. The crystallized solid was collected using high-speed centrifugation (10,000 rpm, 30 min, Heraeus Multifuge X3F Centrifuge, Thermo Fisher Scientific, Waltham, MA, USA) and washed with distilled water until $\mathrm{pH} 7$ before drying at $70^{\circ} \mathrm{C}$ overnight.

\subsection{Preparation of $\mathrm{NiO}$-Supported $\mathrm{Y} 65$}

\subsubsection{Impregnation (IM) Method}

$\mathrm{Ni}\left(\mathrm{NO}_{3}\right)_{2} \cdot 6 \mathrm{H}_{2} \mathrm{O}(1.011 \mathrm{~g}, 10 \mathrm{wt} \% \mathrm{Ni}$ metal basis $(99 \%)$, Merck, Germany) was first dissolved in distilled water $(5 \mathrm{~mL})$ before the parent $Y 65(2.000 \mathrm{~g})$ was added to the solution. The mixture was 
continuously stirred for $30 \mathrm{~min}$ at ambient temperature. While stirring, the solution was then heated and maintained at $80^{\circ} \mathrm{C}$ to evaporate the water. The resulting solid product was dried $\left(70{ }^{\circ} \mathrm{C}, 15 \mathrm{~h}\right)$, ground into fine powder, and calcined $\left(550^{\circ} \mathrm{C}, 4 \mathrm{~h}, 1{ }^{\circ} \mathrm{C} / \mathrm{min}\right)$ to produce the IM-Y 65 catalyst, which is gray in color.

\subsubsection{Deposition-Precipitation (DP) Method with Urea}

Typically, an aqueous solution $(40 \mathrm{~mL})$ containing $\mathrm{Ni}\left(\mathrm{NO}_{3}\right)_{2} \cdot 6 \mathrm{H}_{2} \mathrm{O}(1.011 \mathrm{~g}, 10 \mathrm{wt} \% \mathrm{Ni}$ metal basis) was first prepared, and $30 \mathrm{~mL}$ of the solution was used to make a suspension with parent $\mathrm{Y} 65$ $(2.000 \mathrm{~g})$. Urea ( $2.2741 \mathrm{~g}, 98 \%$, Sigma-Aldrich, Germany), which was equivalent to the Urea:Ni molar ratio of 10:1, was dissolved in the remaining $\mathrm{Ni}\left(\mathrm{NO}_{3}\right)_{2}$ solution. The mixture solution was then added dropwise into the zeolite suspension at $70^{\circ} \mathrm{C}$ before the DP process was initiated at $90^{\circ} \mathrm{C}$. After $2 \mathrm{~h}$ of DP treatment, the suspension was centrifuged (10,000 rpm, $10 \mathrm{~min})$, washed with distilled water until $\mathrm{pH} 7$, oven dried $\left(70{ }^{\circ} \mathrm{C}, 15 \mathrm{~h}\right)$, ground into fine powder and calcined $\left(550^{\circ} \mathrm{C}, 4 \mathrm{~h}, 1{ }^{\circ} \mathrm{C} / \mathrm{min}\right)$ to produce the DP-Y65 catalyst, which is light gray in color.

\subsection{Catalyst Characterization}

The X-ray diffraction (XRD) patterns of the zeolites were recorded using a XRD diffractometer (Empyrean, Malvern PANalytical, UK) $\left(\mathrm{Cu} \mathrm{K} \alpha, \lambda=1.5406 \AA 2,2 \theta=5-50^{\circ}, 1.5 \mathrm{~s}\right.$ per step). The crystallite size of nickel oxide was estimated using the Scherrer equation (Equation (1)):

$$
\mathrm{d}=\frac{\mathrm{K} \lambda}{\beta \cos \theta}
$$

where $\mathrm{K}$ is a dimensionless constant, taken as $0.9 ; \lambda$ is the wavelength of $X$-ray radiation; $\beta$ is the full width at half-maximum (FWHM); and $\theta$ is the diffraction angle. The high resolution transmission electron microscopy (HRTEM) images of the samples were captured with a FEI Tecnai F20 HRTEM microscope (USA) with an accelerating voltage of $200 \mathrm{kV}$. The porosity of the solids was determined by a nitrogen adsorption analyzer (ASAP 2020, Micromeritics, Norcross, GA, USA). Prior to the analysis, the samples were first degassed under a vacuum $\left(300{ }^{\circ} \mathrm{C}, 8 \mathrm{~h}\right)$. The pore size distribution of the samples in micropore $(0.4$ to $1.0 \mathrm{~nm}$ ) and mesopore ( 2 to $50 \mathrm{~nm}$ ) ranges was determined by the density functional theory (DFT) method. The hierarchical factor (H.F) was calculated by using the following equation (Equation (2) [40]:

$$
\mathrm{H} . \mathrm{F}=\frac{\mathrm{V}_{\mathrm{mic}} \times \mathrm{S}_{\mathrm{ext}}}{\mathrm{V}_{\text {tot }} \times \mathrm{S}_{\mathrm{BET}}}
$$

where $V_{\text {mic }}$ is the micropore surface area, $S_{\text {ext }}$ is the external surface area, $V_{\text {tot }}$ is the total pore volume, and $\mathrm{S}_{\mathrm{BET}}$ is the Brunauer-Emmett-Telle (BET) surface area. The chemical composition of the zeolites was determined by using a inductively coupled plasma-optical emission spectrophotometry (ICP-OES) spectrometer (Vista MPX, Varian, Atlanta, GA, USA). The Ni content of the samples were determined by an energy dispersive X-ray (EDX) spectrometer (X-max, Oxford Instruments, UK) with an excitation energy of $15 \mathrm{kV}$. The acidity of the samples was determined by using the temperature programmed desorption-ammonia (TPD- $\mathrm{NH}_{3}$ ) technique with TPD analyzer (TPD/R/O 1100, Thermo Finnigan, USA). The sample $(50 \mathrm{mg})$ was first treated $\left(250^{\circ} \mathrm{C}, 30 \mathrm{~min}\right)$ under a $\mathrm{N}_{2}$ gas flow, followed by saturation with $\mathrm{NH}_{3}$ gas $\left(25^{\circ} \mathrm{C}, 1 \mathrm{~h}\right)$. The excess $\mathrm{NH}_{3}$ was subsequently flushed away with $\mathrm{N}_{2}$ gas flow $(20 \mathrm{~mL} / \mathrm{min}$, $30 \mathrm{~min}$ ). The acidity profile was recorded by a thermal conductivity detector (TCD) detector under helium gas flow $(30 \mathrm{~mL} / \mathrm{min})$ from $50{ }^{\circ} \mathrm{C}$ to $600{ }^{\circ} \mathrm{C}$ with a heating rate of $10{ }^{\circ} \mathrm{C} / \mathrm{min}$ and held for $30 \mathrm{~min}$. The pyridine Fourier transform-infrared spectroscopy (FTIR) spectra were recorded using a FTIR spectrometer (Nicolet 2000, Thermo Fisher Scientific, Waltham, MA, USA). A self-supported wafer (area $2 \mathrm{~cm}^{2}$, mass of 11-12 $\mathrm{mg}$ ) was first prepared before it was inserted into the infrared (IR) cell and degassed under vacuum $\left(10^{-3} \mathrm{mbar}, 400^{\circ} \mathrm{C}, 5 \mathrm{~h}\right)$. The reference spectrum was first recorded after cooling before pyridine (containing $73 \mathrm{ppm} \mathrm{H}_{2} \mathrm{O}$ according to Karl Fischer titration) was introduced to the samples $\left(25^{\circ} \mathrm{C}, 30 \mathrm{~min}\right)$. The sample was evacuated at $200{ }^{\circ} \mathrm{C}$ for $30 \mathrm{~min}$ to remove weakly 
bound pyridine molecules. The concentrations of the Brönsted $\left(C_{\text {Brönsted }}\right)$ and Lewis $\left(C_{\text {Lewis }}\right)$ acid sites were calculated using molar integral extinction coefficients of $\varepsilon_{\text {Brönsted }}=0.73 \mathrm{~cm} / \mu \mathrm{mol}$ and $\varepsilon_{\text {Lewis }}$ $=0.96 \mathrm{~cm} / \mu \mathrm{mol}$ [27]. The coke deposition of the samples was determined by an thermogravimetic analysis (TGA) analysis (STA6000, Perkin Elmer, USA) from 30 to $750{ }^{\circ} \mathrm{C}$ with a heating ramp of $10^{\circ} \mathrm{C} / \mathrm{min}$ and under air condition.

\subsection{Catalytic Deoxygenation of Triolein}

Initially, triolein (10.000 g, glyceryl trioleate, $65 \%$, Sigma-Aldrich, Germany) and a catalyst ( $0.500 \mathrm{~g})$ were added into a $50 \mathrm{~mL}$ semi-batch quartz reactor equipped with a mechanical stirrer, a temperature controller, and a vacuum system. An ice-cold distillation system $\left(4{ }^{\circ} \mathrm{C}\right)$ was used to control the condensation of deoxygenated products. The reaction was performed at $380^{\circ} \mathrm{C}$ for 0.15 to $4 \mathrm{~h}$ with a catalyst loading of 1 to $9 \mathrm{wt} \%$ under stirring ( $400 \mathrm{rpm}$ ) and partial vacuum (10 mbar) conditions without any gas supply. The experiment was performed in triplicates to verify the reproducibility of the reaction.

\subsection{Analysis of Deoxygenated Products}

The fractions of deoxygenated products were analyzed by a Gas Chromatography-Mass Spectrometry (GC-MS) spectrometer (QP2010 Plus, Shimadzu, Kyoto, Japan) with a RTX-5MS column $(30.0 \mathrm{~m} \times 0.25 \mu \mathrm{m} \times 0.25 \mathrm{~mm}$ ). All samples were diluted to $500 \mathrm{ppm}$ with $n$-hexane (Merck) and were spiked with $50 \mathrm{ppm}$ of 1-bromohexane (Merck) as internal standard. The diluted samples $(1 \mu \mathrm{L}$, splitless) were then injected into the GC-MS where the initial oven temperature $\left(40{ }^{\circ} \mathrm{C}\right)$ was raised to $300{ }^{\circ} \mathrm{C}\left(5^{\circ} \mathrm{C} / \mathrm{min}\right)$ and held at $300{ }^{\circ} \mathrm{C}$ for $40 \mathrm{~min}$. The mass spectra were compared with the National Institute of Standards and Testing (NIST) library and standard hydrocarbon solutions of $\mathrm{C}_{8}$ to $\mathrm{C}_{20}$ (Sigma-Aldrich, Malaysia). Meanwhile, the product distribution of deoxygenated liquids was determined by calculating the peak area of the Gas Chromatography (GC) chromatographs. The conversions of triolein (Equation (3)), organic liquid product (OLP) selectivity (Equation (4)), and hydrocarbon selectivity (Equation (5)) were calculated using the following equations, respectively:

$$
\begin{aligned}
& \text { Conversion }(\%)=\frac{\text { Mass of reactant }{ }_{\text {initial }}-\text { Mass of reactant }_{\text {final }}}{\text { Mass of reactant }_{\text {initial }}} \times 100 \% \\
& \text { OLP selectivity }(\%)=\frac{\text { Total Area of Desired Organic Product }}{\text { Total Area of the liquid product }} \times 100 \% \\
& \text { Hydrocarbon selectivity }(\%)=\frac{\text { Area of Hydrocarbon Fraction }}{\text { Total Area of Hydrocarbon C } 8-\mathrm{C} 24} \times 100 \%
\end{aligned}
$$

The initial rate $\left(\mathrm{g}_{\mathrm{oil}} \cdot \mathrm{h}^{-1}\right)$ was calculated based on the conversion of triolein for the first $30 \mathrm{~min}$.

\section{Results and Discussion}

\subsection{Catalyst Characterization}

\subsubsection{X-ray Diffraction (XRD) Analysis}

The XRD diffractograms of parent $\mathrm{Y} 65$ and the supported $\mathrm{NiO}$ catalysts are shown in Figure 1. The parent $Y 65$ shows well-defined diffraction peaks at $2 \theta=6.2^{\circ}, 10.2^{\circ}, 12.0^{\circ}, 15.8^{\circ}, 19.2^{\circ}, 20.5^{\circ}, 23.9^{\circ}$, and $27.0^{\circ}$ due to the (111), (220), (311), (331), (440), (533), (642), and (733) planes of zeolite $Y$, respectively (Figure 1a) [41]. Nevertheless, the addition of $\mathrm{NiO}$ to the zeolite followed by a calcination treatment slightly decreased the crystallinity (Figure 1b,c). As shown in Table 1, the Si/Al ratio of Y65 was 1.94 and was slightly altered after loading with $\mathrm{NiO}$. The $\mathrm{Si} / \mathrm{Al}$ ratio of the IM-Y65 decreased to 1.91. Meanwhile, the Si/Al ratio of DP-Y65 increased up to 1.96. This was consistent with the XRD result in which the diffractograms of DP-Y65 (Figure 1c) was slightly right-shifted but IM-Y65 was more left-shifted 
compared to parent $\mathrm{Y} 65$. This is because the addition of $\mathrm{NiO}$ tends to slightly change the coordination environment of $\mathrm{Si}$ and $\mathrm{Al}$ in the zeolite [42]. The effective doping of $\mathrm{NiO}$ on $\mathrm{Y} 65$ was confirmed by the presence of the diffraction signals at $2 \theta=37.3^{\circ}$ and $43.3^{\circ}$, which corresponded to the (111) and (200) planes of the face-centered cubic NiO (JCPDS 47-1049), respectively [35]. No other XRD peaks or unknown phases were detected. The peaks of NiO of IM-Y65 prepared using the impregnation method (Figure $1 \mathrm{~b}$ ) were sharper and very intense, indicating large $\mathrm{NiO}$ crystallites $(13.2 \mathrm{~nm})$ have been formed. On the contrary, the NiO peaks in DP-Y65 were broader and less intense due to the high dispersion of smaller $\mathrm{NiO}$ crystallites on $\mathrm{Y} 65[43,44]$. However, it is difficult to estimate the crystallite size from the broad XRD peaks. Hence, HRTEM was employed to study the particle size distribution and dispersion of the $\mathrm{NiO}$ nanoparticles.

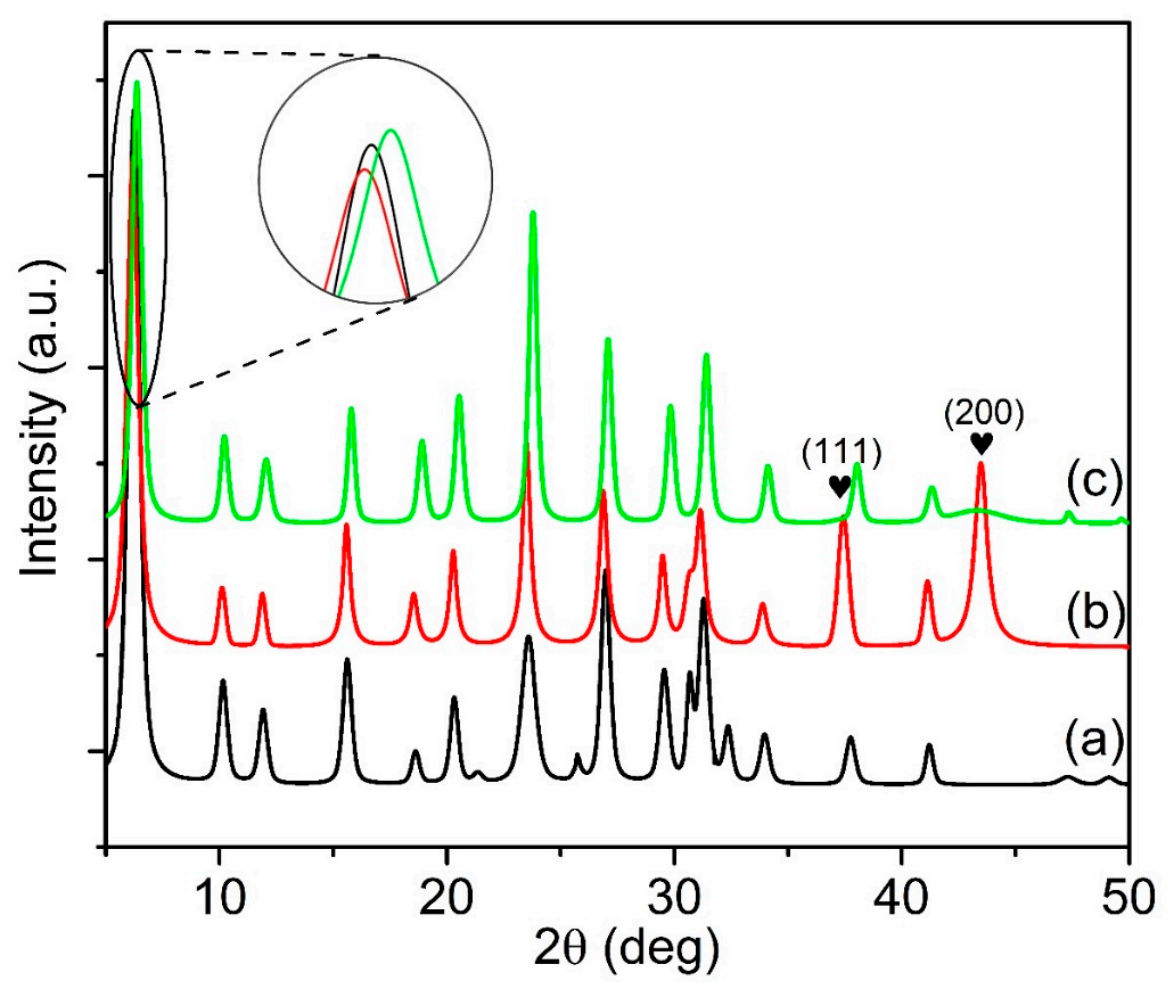

Figure 1. XRD diffractograms of (a) Y65, (b) IM-Y65, and (c) DP-Y65. The symbol indicates the characteristic diffraction peak for nickel oxide.

Table 1. Chemical composition and physical properties of Y65 and NiO-modified Y65.

\begin{tabular}{cccccccccc}
\hline Samples & $\mathbf{S}_{\text {BET }}{ }^{\mathbf{a}}$ & $\mathbf{S}_{\text {mic }}{ }^{\mathbf{b}}$ & $\mathbf{S}_{\text {ext }}{ }^{\mathbf{c}}$ & $\mathbf{V}_{\text {mic }}{ }^{\mathbf{d}}$ & $\begin{array}{c}\mathbf{V}_{\text {meso }} \\
\mathbf{e}\end{array}$ & $\mathbf{V}_{\text {tot }} \mathbf{f}$ & Ni Content $\mathbf{s}$ & $\begin{array}{c}\text { Si/Al } \\
\text { Ratio }\end{array}$ & $\begin{array}{c}\text { Na/Al } \\
\text { Ratio }^{\mathbf{h}}\end{array}$ \\
\hline Y65 & 661 & 599 & 62 & 0.29 & 0.20 & 0.49 & - & 1.94 & 1.04 \\
IM-Y65 & 420 & 377 & 43 & 0.14 & 0.14 & 0.28 & 9.5 & 1.92 & 0.80 \\
DP-Y65 & 503 & 379 & 124 & 0.15 & 0.29 & 0.44 & 10.2 & 1.96 & 0.43 \\
\hline
\end{tabular}

${ }^{\text {a }}$ BET surface area $\left(\mathrm{m}^{2} / \mathrm{g}\right) ;{ }^{\mathrm{b}}$ Micropore surface area $\left(\mathrm{m}^{2} / \mathrm{g}\right) ;{ }^{\mathrm{c}}$ External surface area $\left(\mathrm{m}^{2} / \mathrm{g}\right) ;{ }^{\mathrm{d}}$ Micropore volume $\left(\mathrm{cm}^{3} / \mathrm{g}\right) ;{ }^{\mathrm{e}}$ Mesopore volume $\left(\mathrm{cm}^{3} / \mathrm{g}\right) ;{ }^{\mathrm{f}}$ Total pore volume $\left(\mathrm{cm}^{3} / \mathrm{g}\right) ;{ }^{\mathrm{g}}$ Determined by EDX; ${ }^{\mathrm{h}}$ Determined by ICP-OES.

\subsubsection{HRTEM Analysis}

The HRTEM images of the samples are shown in Figure 2. It is shown that the modification approach plays a key role in controlling the particle size and size distribution of $\mathrm{NiO}$ active species. The $\mathrm{NiO}$ nanoparticles prepared via the IM method were larger, and they tend to aggregate forming large clusters $(12.1 \pm 2.2 \mathrm{~nm}$ ) on the surface of Y65 (Figure 2a). For the DP method, NiO nanoparticles with a much smaller size of $3.57 \pm 0.40 \mathrm{~nm}$ were formed (Figure $2 \mathrm{~b}$ ). In addition, DP methods manage to give a more homogeneous distribution of $\mathrm{NiO}$ on the surface of zeolite. These results are in good 
agreement with the XRD results where IM-Y65 produced larger NiO nanoparticles than DP-Y65 did. The amount of Ni was determined by an EDX analysis. As shown in Table 1, the Ni content in IM-Y65 and DP-Y65 was 9.5 and $10.2 \mathrm{wt} \%$, respectively, which were close to the theoretical Ni content of $10 \mathrm{wt} \%$. It should be borne in mind that the control of the particle size of $\mathrm{NiO}$ is important as it affects the overall physicochemical properties of the solid where the particle size normally is governed by the synthesis conditions. In order to ensure the generation of $\mathrm{NiO}$ particles in the nanometer range, the use of a weak base (e.g., urea) instead of a strong base (e.g., $\mathrm{NaOH}$ ) is important, as urea can slowly release the hydroxide ions without an abrupt change in $\mathrm{pH}$ value $(6,7)$.

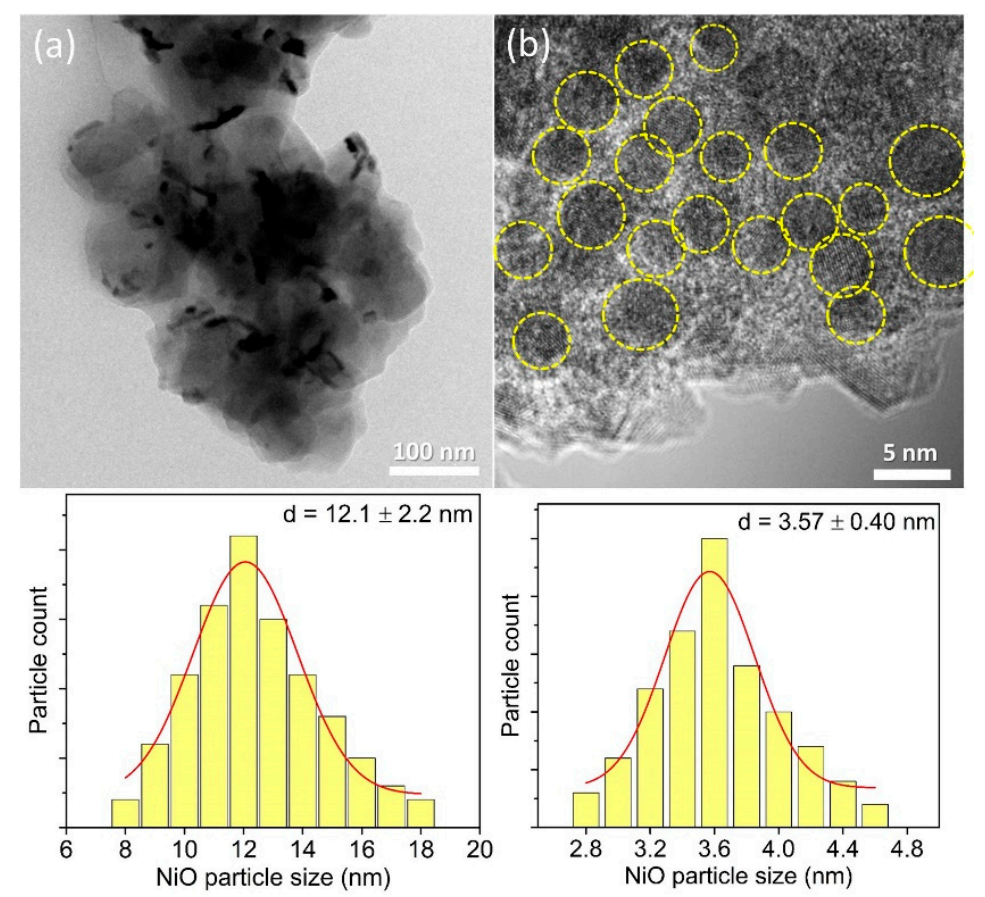

Figure 2. HRTEM images of (a) IM-Y65 and (b) DP-Y65.

\subsection{3. $\mathrm{N}_{2}$ Sorption Analysis}

The addition of $\mathrm{NiO}$ nanoparticles on the zeolite support might influence the surface porous properties, and hence an $\mathrm{N}_{2}$ sorption isotherm analysis is performed. The parent Y65 shows a combination of types I and IV isotherm and a large H4-type hysteresis at high $\mathrm{P} / \mathrm{P}_{\mathrm{O}}$ due to the presence of intercrystal mesoporosity ((a) in Figure 3A) [45]. The mesoporosity appeared due to the crystal packing of nanosized zeolite crystals [46]. It possessed a $S_{B E T}$ and a $V_{\text {tot }}$ of $661 \mathrm{~m}^{2} / \mathrm{g}$ and $0.49 \mathrm{~cm}^{3} / \mathrm{g}$, respectively. When the $\mathrm{NiO}$ nanoparticles are formed on the zeolite support by means of various methods, the IM-Y65 and DP-Y65 still exhibit type I and IV isotherms but with lower $\mathrm{N}_{2}$ uptake ((b, c) in Figure 3A). As shown by the pore size distribution in the micropore region $(0.4-1.0 \mathrm{~nm})$, the parent Y65 possessed a micropore size of $0.73 \mathrm{~nm}$. The micropore size slightly decreased to about $0.70 \mathrm{~nm}$ with lower intensity after the modification. This observation indicates that some micropores (especially IM-Y65) were occupied by the $\mathrm{Ni}^{2+}$ ions through the ion-exchange aside from the partial dissolution of the zeolite framework as shown by the decrease in zeolite crystallinity after the modifications [14,35] $((b, c)$ in Figure $3 A)$. As a result, lower values of $S_{B E T}, S_{m i c}, V_{\text {mic }}$ and $V_{\text {tot }}$ were recorded. Nevertheless, the $S_{\text {ext }}$ of DP-Y65 increased nearly one-fold (from 62 to $124 \mathrm{~m}^{2} / \mathrm{g}$ ), but the IM-Y65 experienced a slight decrease in the $S_{\text {ext }}\left(43 \mathrm{~m}^{2} / \mathrm{g}\right)$. The difference in $S_{\text {ext }}$ observed in these samples can be explained by the different particle sizes of the $\mathrm{NiO}$ nanoparticles distributed on the zeolite surface where smaller $\mathrm{NiO}$ particles have a higher surface area than the larger one [28]. The $\mathrm{NiO}$ addition also affect the molecular diffusion properties of the supported catalysts, and hence the hierarchical factor (H.F) of the zeolite samples was calculated. As seen, the H.F value of IM-Y65 slightly decreased from 0.056 to 
0.052 when it was modified with $\mathrm{NiO}$ impregnation (Table 2). Interestingly, the H.F value increased to 0.084 for DP-Y65, implying that the diffusion of bulky molecules such as triolein in this catalyst is significantly improved.
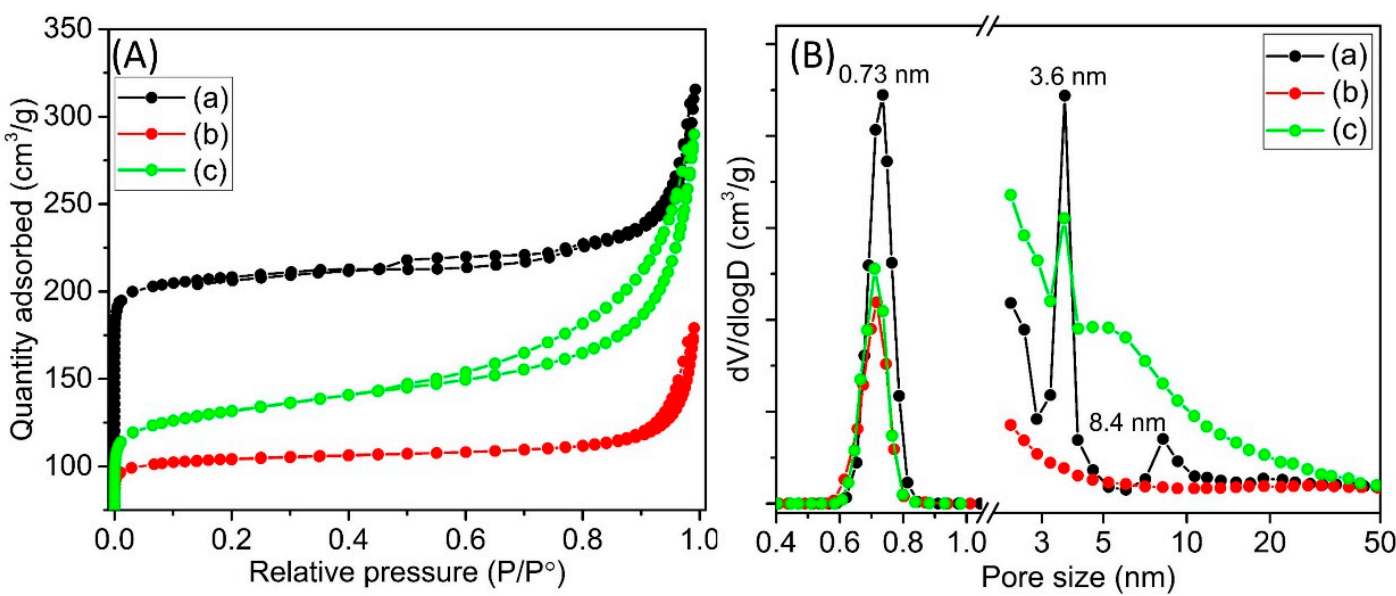

Figure 3. (A) $\mathrm{N}_{2}$ sorption isotherms and (B) pore size distribution of (a) Y65, (b) IM-Y65, and (c) DP-Y65.

Table 2. Surface acidity of Y65 and NiO-modified Y65.

\begin{tabular}{|c|c|c|c|c|c|c|c|c|c|}
\hline \multirow[b]{2}{*}{ Samples } & \multicolumn{4}{|c|}{$\mathrm{TPD}^{-\mathrm{NH}_{3}}$ Acidity $(\mathrm{mmol} / \mathrm{g})$} & \multicolumn{4}{|c|}{ Py-FTIR Acidity $(\mathrm{mmol} / \mathrm{g})$ at $200^{\circ} \mathrm{C}$} & \multirow[b]{2}{*}{ H.F ${ }^{a}$} \\
\hline & Weak & Medium & $\begin{array}{l}\text { Medium- } \\
\text { Strong }\end{array}$ & Total & $\begin{array}{l}\text { Brönsted } \\
\text { (B) }\end{array}$ & $\begin{array}{l}\text { Lewis } \\
\text { (L) }\end{array}$ & $\begin{array}{l}\text { Total Acid } \\
(\mathrm{B}+\mathrm{L})\end{array}$ & $\begin{array}{c}\text { B/L } \\
\text { Ratio }\end{array}$ & \\
\hline Y65 & 1.09 & 0.82 & 2.70 & 4.62 & 0.38 & 1.39 & 1.77 & 0.27 & 0.056 \\
\hline IM-Y65 & 1.29 & 0.92 & 1.14 & 3.35 & 0.10 & 1.18 & 1.28 & 0.08 & 0.052 \\
\hline DP-Y65 & 0.63 & 1.94 & 2.10 & 4.67 & 0.50 & 1.72 & 2.22 & 0.29 & 0.084 \\
\hline
\end{tabular}

In terms of mesoporosity, the parent Y65 contains two different mesopores of 3.6 and $8.4 \mathrm{~nm}$. However, these mesopores disappear in the IM-Y65 sample, which clearly indicates that the large $\mathrm{NiO}$ particles prepared by the IM method not only occupy the micropores, but they also covered the intercrystal mesopores of the zeolite. For DP-Y65, the number of the $3.6 \mathrm{~nm}$ mesopore was reduced while the mesopore of $8.4 \mathrm{~nm}$ disappeared and subsequently a new mesopore size shouldered at $5.0 \mathrm{~nm}$ was formed. This result suggests that some $\mathrm{NiO}$ nanoparticles (ca. $3.6 \mathrm{~nm}$ ) have entered the large mesopore $(8.4 \mathrm{~nm})$ and therefore result in the shrinkage of the mesopore to $5.0 \mathrm{~nm}$. The pore size distribution analysis is in good agreement with the results reported by Cheng et al., where the mesopore diameter was slightly decreased after loading with metal nanoparticles [47].

\subsubsection{TPD-NH${ }_{3}$ and Pyridine-FTIR Analysis}

Figure $4 \mathrm{~A}$ shows the TPD-NH 3 profiles of the parent and NiO-modified Y65 zeolite samples. The deconvolution of the TPD- $\mathrm{NH}_{3}$ profiles give rise to the acid sites with different acidity strengths. As shown, parent $\mathrm{Y} 65$ exhibited three deconvoluted peaks at 126,278 , and $325^{\circ} \mathrm{C}$ which corresponded to the weak, medium, and medium-strong acid sites ((a) in Figure $4 \mathrm{~A})$. When the NiO nanoparticles were supported on the Y65 using different approaches, a significant change in the acid strength was observed in the resulting $\mathrm{NiO}$-modified Y65. As discussed earlier, the change in the Si/Al ratio is minimal, and therefore the change in acidity profile was primarily due to the $\mathrm{NiO}$ modifications. The acid strength was reduced across the NiO-modified Y65 as the maximum of medium strength acidities at $278{ }^{\circ} \mathrm{C}$ was shifted to the range of 153 and $167{ }^{\circ} \mathrm{C}$. At the same time, the maximum of medium-strong acidity $\left(325^{\circ} \mathrm{C}\right)$ was shifted to a lower desorption temperature $\left(216-309{ }^{\circ} \mathrm{C}\right)$ as well. Only the DP-Y65 retained the medium-strong acidity of parent Y65, although the desorption 
temperatures are slightly lower ( 309 and $325^{\circ} \mathrm{C}$, respectively). This is due to the fact that some of the acid sites of zeolite $\mathrm{Y}$ have been covered by $\mathrm{NiO}$ nanoparticles [20]. The amount of the medium-strong IM-Y65 was $1.14 \mathrm{mmol} / \mathrm{g}$ (Table 2). This value was significantly lower than those of parent $Y 65$ and DP-Y65 (2.70 and $2.10 \mathrm{mmol} / \mathrm{g}$, respectively). Nevertheless, the amount of medium strength acidity has increased from $0.82 \mathrm{mmol} / \mathrm{g}$ (parent Y65) to the range of $0.92-2.32 \mathrm{mmol} / \mathrm{g}$ after supporting with $\mathrm{NiO}$ nanoparticles, revealing that $\mathrm{NiO}$ introduces medium strength acidity onto the zeolite support.
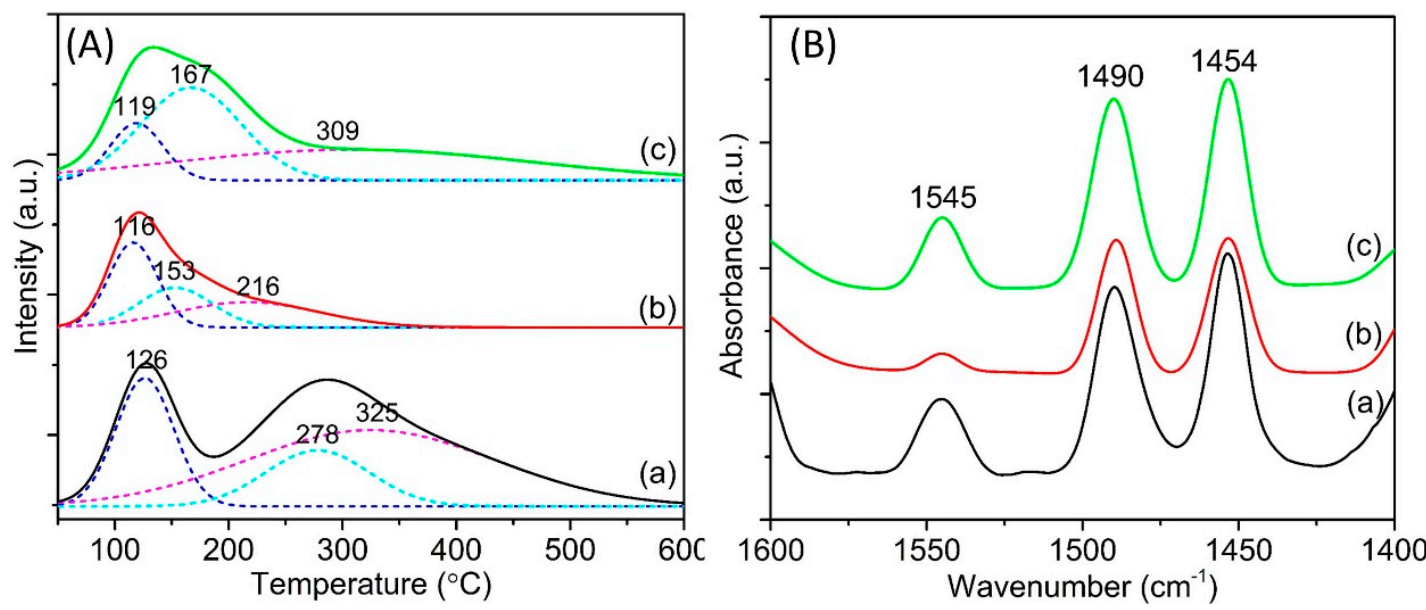

Figure 4. (A) TPD- $\mathrm{NH}_{3}$ profiles and (B) pyridine-FTIR spectra of (a) Parent Y65, (b) IM-Y65, and (c) DP-Y65.

The distribution of Brönsted and Lewis acid sites in the samples were studied by using pyridine-FTIR and is shown in Figure 4B. The IR bands located at 1545, 1490, and $1454 \mathrm{~cm}^{-1}$ correspond to the Brönsted acid sites (B), the total acidity (B+L), and the Lewis acid sites (L), respectively [48]. When the $\mathrm{NiO}$ nanoparticles were introduced onto the parent $\mathrm{Y} 65$ by impregnation (IM-Y65), the Brönsted acidity has decreased significantly whereas DP-Y65 still shows considerably high peak intensity. The reduction in Brönsted acidity is expected due to the loss in zeolite crystallinity (as shown by the XRD and BET results) and the occupying of $\mathrm{NiO}$ on the Brönsted acid sites. On the other hand, the Lewis acidity increased with the addition of $\mathrm{NiO}$ nanoparticles, which is in line with the observation reported in Ref. [49]. The pyridine-FTIR data are also tabulated in Table 2. DP-Y65 has the highest $\mathrm{B} / \mathrm{L}$ ratio $(0.29)$ while the IM-Y 65 has a relatively lower $\mathrm{B} / \mathrm{L}$ ratio $(0.08)$. The high Brönsted acidity of DP-Y 65 can be due to the partial decomposition of the $\mathrm{NH}_{4}{ }^{+}$ion to $\mathrm{H}^{+}$during the synthesis calcination step. The $\mathrm{NH}_{4}{ }^{+}$ions were produced from the decomposition of urea (Equation (6)).

$$
\mathrm{CO}\left(\mathrm{NH}_{2}\right)_{2}+3 \mathrm{H}_{2} \mathrm{O} \rightarrow 2 \mathrm{NH}_{4}^{+}+\mathrm{HCO}_{3}^{-}+\mathrm{OH}^{-}
$$

The partial exchange of the $\mathrm{Na}^{+}$ion with $\mathrm{NH}_{4}{ }^{+}$ion in DP-Y65 can be proven by the band at $1440 \mathrm{~cm}^{-1}$, which corresponds to the $\mathrm{NH}_{4}{ }^{+}$[50] (see Supporting Information: Figure S1). This signal disappeared after the calcination step, indicating that the $\mathrm{NH}_{4}{ }^{+}$has been decomposed into $\mathrm{H}^{+}$and $\mathrm{NH}_{3}$. In addition, this claim can also be proven by the decrease seen in the $\mathrm{Na} / \mathrm{Al}$ ratio of DP-Y65 (0.43) as compared to that of IM-Y65 (0.80), which is shown in Table 1. Hence, the DP method using urea not only is able to produce smaller $\mathrm{NiO}$ nanoparticles, but it also introduces the Brönsted acidity to the NaY zeolite.

\subsection{Catalytic Deoxygenation Activity}

The deoxygenation reaction of triolein over the parent $\mathrm{Y} 65$ and NiO-modified Y65 prepared by a different synthesis method was determined and is shown in Figure 5. Parent Y65 only shows a $20.8 \%$ triolein conversion after reacting at $380^{\circ} \mathrm{C}$ for $0.5 \mathrm{~h}$ (initial rate: $4.2 \mathrm{~g}_{\text {oil }} \cdot \mathrm{h}^{-1}$ ). The deoxygenation 
performance of the NiO-modified Y65 was significantly improved as its initial rates were at least doubled than that of parent Y. Specifically, DP-Y65 revealed the highest triolein conversion of $74.0 \%$, equivalent to the initial rate of $14.8 \mathrm{goil}_{\mathrm{oil}} \cdot \mathrm{h}^{-1}$. In contrast, IM-Y 65 showed a triolein conversion of $46.2 \%$ or $9.6 \mathrm{~g}_{\mathrm{oil}} \cdot \mathrm{h}^{-1}$. In terms of liquid product distribution, the deoxygenated liquid of parent $\mathrm{Y} 65$ contains $65.45 \% \mathrm{C}_{8}-\mathrm{C}_{20}$ hydrocarbon. For NiO-modified $\mathrm{Y} 65$, DP-Y 65 showed a higher $\mathrm{C}_{8}-\mathrm{C}_{20}$ hydrocarbon selectivity (88.9\%) than IM-Y65 did (78.2\%). Despite having the same amount of Ni content (10 wt \%) used in the preparation of $\mathrm{NiO}$, different deoxygenation performances were obtained. This result clearly shows that the deoxygenation of triolein is greatly influenced by the physicochemical properties of the NiO-modified zeolite. DP-Y65 exhibited a smaller NiO particle size $(3.57 \mathrm{~nm})$, a larger external surface area $\left(124 \mathrm{~m}^{2} / \mathrm{g}\right)$, a higher medium and medium-strong acidity with high $\mathrm{B} / \mathrm{L}$ ratio $(0.29)$, which has facilitated the diffusion of large triolein molecules $(\sim 4.4 \mathrm{~nm})$ into the active site and transformed them into deoxygenated products [51]. In contrast, the low external surface area and less medium strength acidity of IM-Y65 shows lower deoxygenation activity.
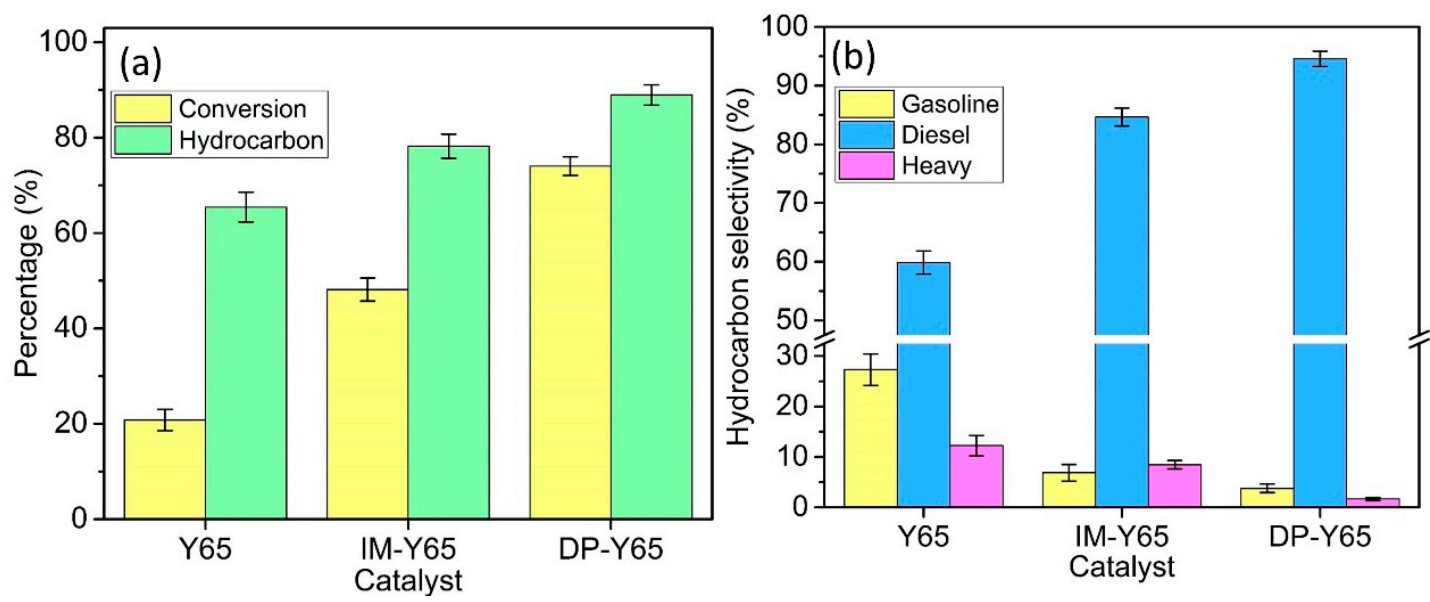

Figure 5. (a) Comparison study of conversion and hydrocarbon product and (b) hydrocarbon selectivity from deoxygenation of triolein over synthesized catalysts.

The $65 \mathrm{wt} \%$ triolein mainly consists of $\mathrm{C}_{16}$ and $\mathrm{C}_{18}$ fatty acids and a trace amount of other $\mathrm{C}_{14}$ to $\mathrm{C}_{20}$ fatty acids [52]. As we mentioned earlier, the deoxygenation route in the hydrogen-free condition is dominated by the DCO route instead of the HDO route, which requires a high pressure of $\mathrm{H}_{2}$. Theoretically, the deoxygenation of triolein in the hydrogen-free condition will produce $\mathrm{C}_{15}$ and $\mathrm{C}_{17}$ hydrocarbon. However, in the real deoxygenation condition, there are many side reactions that occur, such as cracking and polymerization, which will result in hydrocarbon with different chain lengths. The hydrocarbon can be classified into gasoline, diesel, and heavy hydrocarbon according to their carbon chain length $[26,39]$. As shown in Figure $5 b$, the liquid product of parent $Y 65$ contained $27.3 \%$ gasoline $\left(C_{8}-C_{12}\right), 59.8 \%$ of diesel $\left(C_{13}-C_{18}\right)$, and $12.3 \%$ of heavy hydrocarbon $\left(C_{19+}\right)$. The high gasoline content on the parent $\mathrm{Y} 65$ may due to the large amount of strong acidity, which facilitates the cracking reaction. The amount of strong acid sites of the NiO-modified $\mathrm{Y} 65$ were reduced according to the acidity characterization. As a result, the addition of $\mathrm{NiO}$ on the $\mathrm{Y} 65$ has greatly improved the diesel selectivity to more than $84.6 \%$. Among the NiO-modified Y65, DP-Y65 showed a higher diesel selectivity (94.6\%) than IM-Y65 (84.6\%). At the same time, a low selectivity towards gasoline (3.8\%) and heavy hydrocarbon (1.7\%) on DP-Y65 indicated that the occurrence of cracking and polymerization was very rare. This result is very promising as the polymerization of an organic product will result in the formation of coke, which in turns increase the possibility of catalyst deactivation. 


\subsection{Effect of Catalyst Loading}

Figure 6 shows the conversion, hydrocarbon distribution, and selectivity as a function of catalyst loading ( 1 to $9 \mathrm{wt} \%$ ) at $380{ }^{\circ} \mathrm{C}$ for $0.5 \mathrm{~h}$. Based on the result, the range of catalysts from 1 to $7 \mathrm{wt} \%$ showed improvement in the deoxygenation performance. The triolein conversion gradually increased from $51.1 \%(1 \mathrm{wt} \%)$ to $76.6 \%(7 \mathrm{wt} \%)$. At the same time, the hydrocarbon selectivity also improved from $76.29 \%(1 \mathrm{wt} \%)$ to $89.8 \%$ ( $7 \mathrm{wt} \%)$. This improvement is due to the increase of the active site as the catalyst loading increased. In terms of the diesel range hydrocarbon, it progressively increased from $85.8 \%(1 \mathrm{wt} \%)$ to $94.6 \%(7 \mathrm{wt} \%)$ and decreased to $92.8 \%$ at the catalyst loading of $9 \mathrm{wt} \%$. The best result was obtained with $7 \mathrm{wt} \%$ catalyst loading. The increased catalyst loading to $9 \mathrm{wt} \%$ has slightly decreased the performance of deoxygenation. It suggests that an excessive amount of catalyst loading might lead to the occurrence of side reaction such as cracking and polymerization. This can be seen through the slight increase in the gasoline and heavy hydrocarbon at $9 \mathrm{wt} \%(3.6 \%$ and $3.53 \%$, respectively). Therefore, a $7 \mathrm{wt} \%$ catalyst loading was the most suitable since it resulted in the optimal triolein conversion $(76.6 \%)$, hydrocarbon selectivity $(89.8 \%)$, and diesel range hydrocarbon selectivity $(94.6 \%)$.
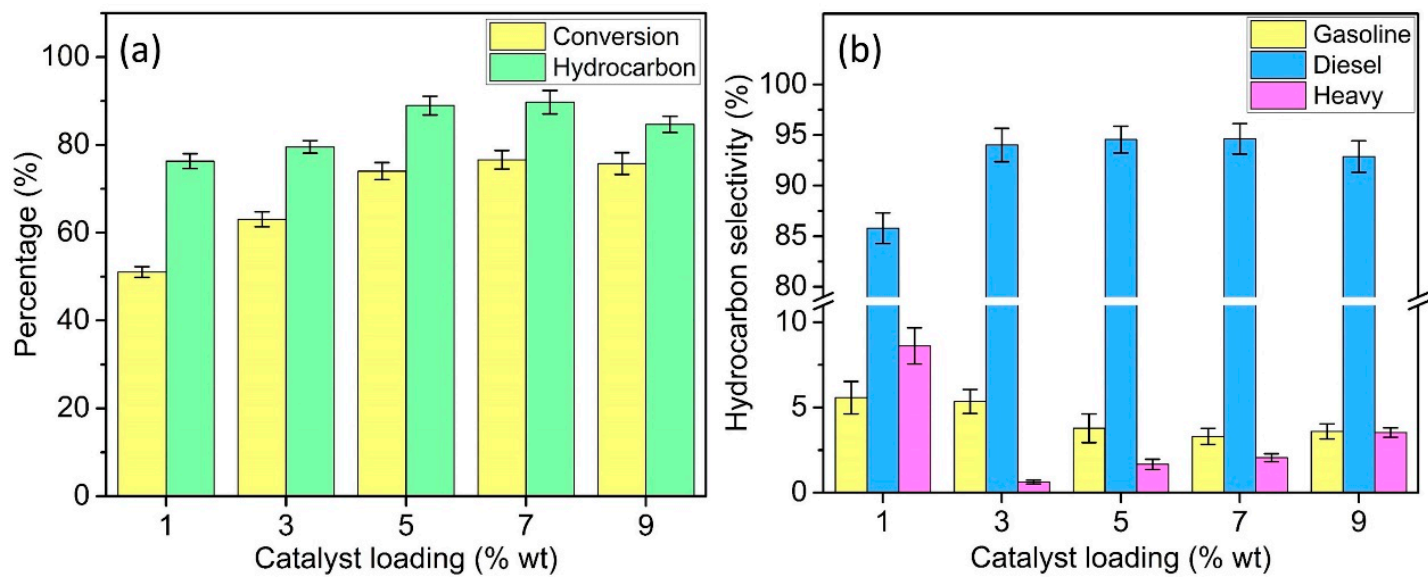

Figure 6. Effect of catalyst loading on (a) conversion and hydrocarbon product and (b) hydrocarbon selectivity from deoxygenation of triolein over DP-Y65.

\subsection{Effect of Reaction Time}

Figure 7 shows the conversion, hydrocarbon distribution, and selectivity as a function of reaction time $\left(0.15\right.$ to $2 \mathrm{~h}$ ) at $380{ }^{\circ} \mathrm{C}$ with a catalyst loading of $7 \mathrm{wt} \%$. As shown in Figure $7 \mathrm{a}$, the triolein conversion progressively increased from $29.0 \%$ at $0.15 \mathrm{~h}$ to $80.0 \%$ at $1 \mathrm{~h}$ and remained at a plateau at $2 \mathrm{~h}$. At the same time, the hydrocarbon selectivity has increased from $79.5 \%$ at $0.15 \mathrm{~h}$ to a maximum of $90.3 \%$ at $1 \mathrm{~h}$ before decreasing to $87.5 \%$ at $2 \mathrm{~h}$. In terms of diesel range hydrocarbon selectivity, it increased from $90.3 \%$ at $0.15 \mathrm{~h}$ to $94.63 \%$ at $0.5 \mathrm{~h}$ and slightly declined to $92.4 \%$ at $2 \mathrm{~h}$. The selectivity for heavy hydrocarbon decreased from $7.6 \%$ at $0.15 \mathrm{~h}$ to $1.6 \%$ at $1 \mathrm{~h}$ before increasing to $2.6 \%$ at $2 \mathrm{~h}$, while for the gasoline range hydrocarbon, it increased as the reaction time increased. This is due to the longer residence time on the catalyst surface, which could facilitate the decarboxylation reaction. Nevertheless, an excessive long reaction time can lead to product cracking and polymerization, which reduces the amount of diesel range hydrocarbon. Therefore, a $1 \mathrm{~h}$ reaction time was the most suitable and economical since it has a relatively high triolein conversion and product selectivity. 

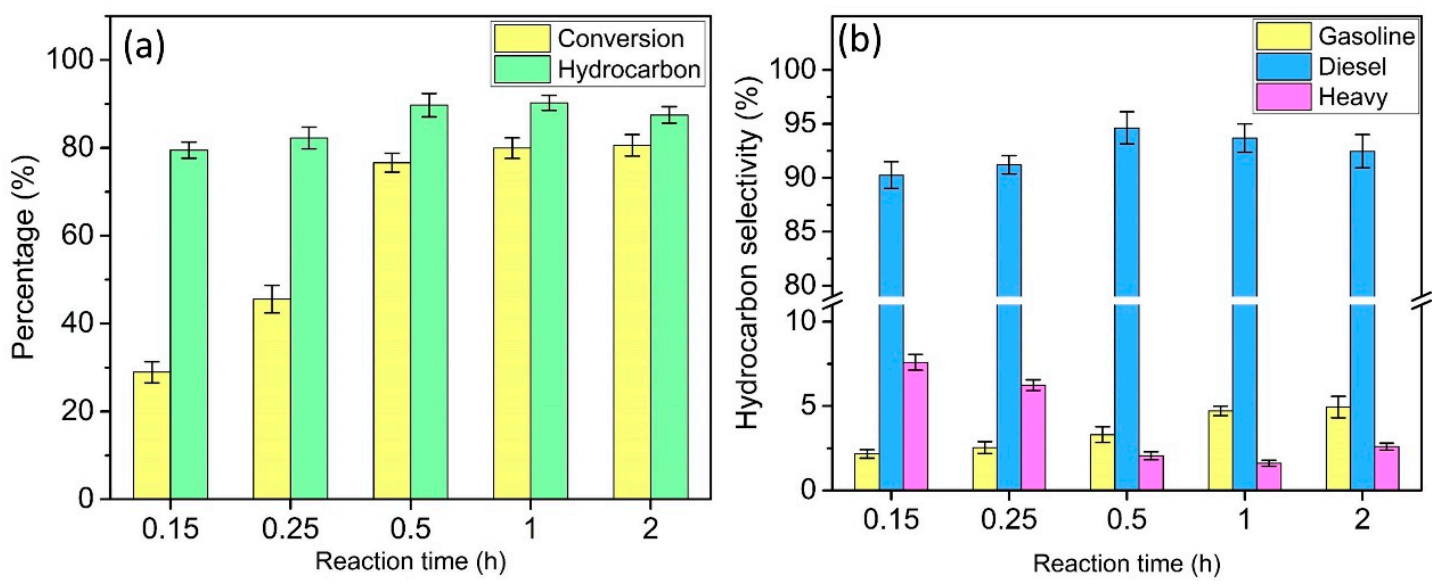

Figure 7. Effect of reaction time on (a) conversion and hydrocarbon product and (b) hydrocarbon selectivity from deoxygenation of triolein over DP-Y65.

\subsection{Reusability}

Catalyst reusability is a very important aspect in the catalysis as it will reduce the overall production cost if the catalyst has a very long shelf life. The catalyst reusability study of DP-Y65 was further investigated at $380^{\circ} \mathrm{C}$ for $1 \mathrm{~h}$ with a $7 \mathrm{wt} \%$ catalyst loading. As shown in Figure 8, the deoxygenation activity of the DP-Y65 decreased across the consecutive runs. The triolein conversion decreased progressively from $80.0 \%$ from the 1 st run to $68.1 \%$ at the 4 th run. In terms of product selectivity, the hydrocarbon selectivity and the diesel range hydrocarbon decreased while the selectivity towards gasoline and heavy hydrocarbon was increased. Based on the XRD result (Figure S2), the recycled catalyst was still showing the same diffraction pattern as the fresh catalyst. This suggests that the recycled catalyst still maintained the framework stability after consecutive reactions. A TGA analysis was carried out to study the extent of coke formation of the catalyst surface. As shown in Figure S3, the fresh DP-Y65 shows a total weight loss about $20.6 \%$ while the recycled DP-Y65 shows a total weight loss of about $18.5 \%$. Based on the derivative thermogravimetric (DTG) result, the weight loss of fresh DP-Y65 with a DTG signal at $118^{\circ} \mathrm{C}$ corresponds to the physisorbed water or trapped solvent. The recycled DP-Y65 showed two additional DTG signals at 466 and $638^{\circ} \mathrm{C}$, which correspond to the decomposition of coke with different hardnesses [49]. The amount of coke deposited on the DP-Y65 was $14.64 \%$ based on the weight loss between 250 and $750{ }^{\circ} \mathrm{C}$. Although the small NiO nanoparticles supported on Y65 is capable of increasing deoxygenation performance, the formation of hard coke with a DTG signal at $638^{\circ} \mathrm{C}$ has led to the decreased performance in the reusability studies. This can be due to the reduced mesoporosity after loading with $\mathrm{NiO}$, as evidenced by the $\mathrm{N}_{2}$ sorption analysis in previous section. Therefore, it is important for the future studies to include the investigation of mesoporosity in the zeolite to obtain a better catalyst for biofuel production through $\mathrm{H}_{2}$-free deoxygenation. 

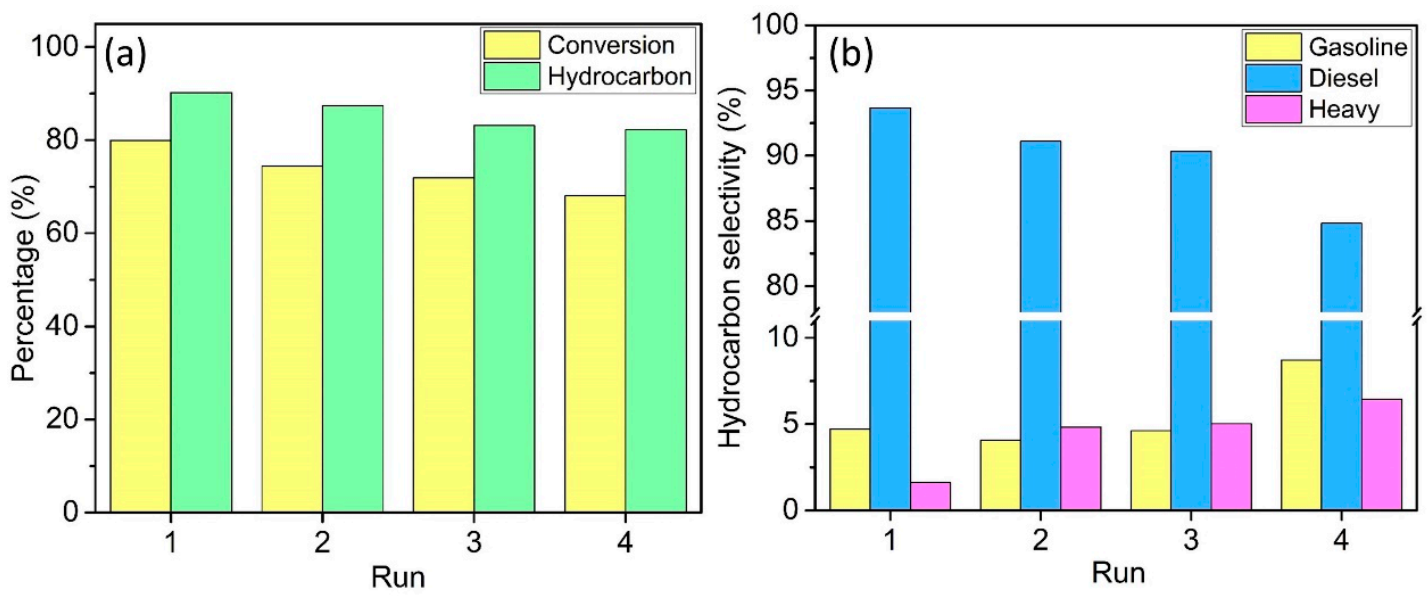

Figure 8. Reusability study of (a) conversion and hydrocarbon product and (b) hydrocarbon selectivity from deoxygenation of triolein over DP-Y65. Reaction conditions: temperature $380^{\circ} \mathrm{C}$, time $1 \mathrm{~h}$, catalyst loading $7 \mathrm{wt} \%$, pressure $10 \mathrm{mbar}$, and stirring speed $400 \mathrm{rpm}$.

\section{Conclusions}

In conclusion, the $10 \mathrm{wt} \%$ of $\mathrm{NiO}$ supported on the nanosized $\mathrm{Y} 65$ were successfully synthesized with two synthesis methods, namely IM and DP. The modification of the NiO onto zeolite $\mathrm{Y}$ has improved the deoxygenation performance of triolein in the absence of hydrogen and solvent conditions. Parent Y65 only showed a $20.8 \%$ triolein conversion with a $65.45 \%$ hydrocarbon distribution and a $59.8 \%$ diesel range hydrocarbon after reacting at $380{ }^{\circ} \mathrm{C}$ for $0.5 \mathrm{~h}$ with $5 \mathrm{wt} \%$ catalyst loading. After loading with $10 \mathrm{wt} \%$ of $\mathrm{NiO}$, the deoxygenation activity was significantly improved. The initial rate was at least doubled that that of parent $Y 65$, which were $>9.6 \mathrm{goil}^{\circ} \cdot \mathrm{h}^{-1}$ and $4.2 \mathrm{~g}_{\mathrm{oil}} \cdot \mathrm{h}^{-1}$, respectively. In terms of product selectivity, $>78.2 \%$ hydrocarbon product and $>84.6 \%$ diesel range hydrocarbon was attained. However, different synthesis methods have a decisive role in the final deoxygenation performance of $\mathrm{NiO}$ supported on $\mathrm{Y} 65$. DP-Y65 showed 1.5 times enhancement in the initial rate as compared to IM-Y65, which were $14.8 \mathrm{~g}_{\mathrm{oil}} \cdot \mathrm{h}^{-1}$ and $9.6 \mathrm{~g}_{\mathrm{oil}} \cdot \mathrm{h}^{-1}$, respectively. The superior performance of the DP-Y65 was due to the synergistic effect of (a) small-sized NiO particles $(\sim 3.6 \mathrm{~nm})$, (b) high H.F value $(0.084)$, and (c) high B/L ratio (0.29). Comparing to the IM method, the DP method is able to produce metal oxide with a smaller nanoparticle size and improve the acidity profile of the Na-form zeolite. Thus, the DP method is ideal for the preparation of metal oxide nanoparticles supported on Na-form zeolite with enhanced acidity. Meanwhile, the DP-Y65 showed the highest triolein conversion (80.0\%), a 90.3\% hydrocarbon distribution, and a $93.7 \%$ diesel range hydrocarbon at $380^{\circ} \mathrm{C}$ for $1 \mathrm{~h}$ with $7 \mathrm{wt} \%$ catalyst loading. However, the reusability studies suggest that the deactivation of deoxygenation reaction was due to the deposition of coke. This coke deposition may due to the decrease of mesoporosity after $\mathrm{NiO}$ modification, which reduces the diffusion of the heavy hydrocarbon from the zeolite. Therefore, it is important for future studies to include the investigation of mesoporosity in the zeolite in order to obtain a better catalyst for biofuel production through $\mathrm{H}_{2}$-free deoxygenation.

Supplementary Materials: The following are available online at http://www.mdpi.com/1996-1944/13/14/3104/s1, Figure S1. FTIR spectra of (a) uncalcined DP-Y65 and (b) calcined DP-Y65.; Figure S2. XRD diffractograms of (a) fresh DP-Y65 and (b) used DP-Y65 after 4th consecutive catalytic reaction runs; Figure S3. TG/DTG thermograms of (a) fresh DP-Y65 and (b) used DP-Y65 after 4th catalytic reaction runs.

Author Contributions: Planning studies, formal analysis, results validation, writing-original draft, M.-Y.C.; Formal analysis, L.E.O.; Formal analysis, T.J.D.; Supervision, research funding, writing-review and editing, formal analysis, T.C.L.; Formal analysis, Y.-C.L.; Formal analysis, G.C.; Supervision, writing-review and editing, E.-P.N.; Supervision, project administration, research funding, writing-review and editing, J.C.J. All authors have read and agreed to the published version of the manuscript. 
Funding: The study was supported by the Fundamental Research Grant Scheme (FP029-2017A), SATU Joint Research Scheme (ST009-2017), Research University Grants (RU018D-2016), and IPPP Postgraduate Research Grant (PG013-2015B).

Conflicts of Interest: The authors declare no conflict of interest.

\section{References}

1. International Energy Agency (IEA). Global Energy \& $\mathrm{CO}_{2}$ Status Report; International Energy Agency (IEA): Paris, France, 2018.

2. U.S. Energy Information Administration. Use of Energy Explained: Energy Use for Transportation 2019. Available online: https://www.eia.gov/energyexplained/use-of-energy/transportation.php (accessed on 6 November 2019).

3. Hussein, A.K. Applications of nanotechnology in renewable energies-A comprehensive overview and understanding. Renew. Sustain. Energy Rev. 2015, 42, 460-476. [CrossRef]

4. Hanaki, K.; Portugal-Pereira, J. The Effect of Biofuel Production on Greenhouse Gas Emission Reductions. In Biofuels and Sustainability: Holistic Perspectives for Policy-Making; Takeuchi, K., Shiroyama, H., Saito, O., Matsuura, M., Eds.; Springer: Tokyo, Japan, 2018; pp. 53-71.

5. Choo, M.-Y.; Oi, L.E.; Show, P.L.; Chang, J.-S.; Ling, T.C.; Ng, E.-P.; Phang, S.M.; Juan, J.C. Recent progress in catalytic conversion of microalgae oil to green hydrocarbon: A review. J. Taiwan Inst. Chem. Eng. 2017, 79 (Suppl. C), 116-124. [CrossRef]

6. Chen, G.; Shan, R.; Shi, J.; Liu, C.; Yan, B. Biodiesel production from palm oil using active and stable K doped hydroxyapatite catalysts. Energy Convers. Manag. 2015, 98, 463-469. [CrossRef]

7. Nasreen, S.; Liu, H.; Skala, D.; Waseem, A.; Wan, L. Preparation of biodiesel from soybean oil using La/Mn oxide catalyst. Fuel Process Technol. 2015, 131, 290-296. [CrossRef]

8. Ullah, Z.; Bustam, M.A.; Man, Z. Biodiesel production from waste cooking oil by acidic ionic liquid as a catalyst. Renew. Energ. 2015, 77, 521-526. [CrossRef]

9. Tan, C.H.; Show, P.L.; Chang, J.-S.; Ling, T.C.; Lan, J.C.-W. Novel approaches of producing bioenergies from microalgae: A recent review. Biotechnol. Adv. 2015, 33 Pt 2, 1219-1227. [CrossRef]

10. Wang, Y.-Y.; Chen, B.-H. High-silica zeolite beta as a heterogeneous catalyst in transesterification of triolein for biodiesel production. Catal. Today 2016, 278 Pt 2, 335-343. [CrossRef]

11. Zandonai, C.H.; Yassue-Cordeiro, P.H.; Castellã-Pergher, S.B.; Scaliante, M.H.N.O.; Fernandes-Machado, N.R.C. Production of petroleum-like synthetic fuel by hydrocracking of crude soybean oil over ZSM5 zeolite-Improvement of catalyst lifetime by ion exchange. Fuel 2016, 172, 228-237. [CrossRef]

12. Chandran, D. Compatibility of diesel engine materials with biodiesel fuel. Renew. Energy 2020, 147, 89-99. [CrossRef]

13. Mofijur, M.; Rasul, M.; Hassan, N.M.S.; Uddin, M.N. Investigation of exhaust emissions from a stationary diesel engine fuelled with biodiesel. Energy Procedia 2019, 160, 791-797. [CrossRef]

14. Srifa, A.; Faungnawakij, K.; Itthibenchapong, V.; Assabumrungrat, S. Roles of monometallic catalysts in hydrodeoxygenation of palm oil to green diesel. Chem. Eng. J. 2015, 278, 249-258. [CrossRef]

15. Chi, J.; Yu, H. Water electrolysis based on renewable energy for hydrogen production. Chin. J. Catal. 2018, 39, 390-394. [CrossRef]

16. Asikin-Mijan, N.; Lee, H.V.; Juan, J.C.; Noorsaadah, A.R.; Abdulkareem-Alsultan, G.; Arumugam, M.; Taufiq-Yap, Y.H. Waste clamshell-derived $\mathrm{CaO}$ supported $\mathrm{Co}$ and $\mathrm{W}$ catalysts for renewable fuels production via cracking-deoxygenation of triolein. J. Anal. Appl. Pyrolysis 2016, 120, 110-120. [CrossRef]

17. Ooi, X.Y.; Oi, L.E.; Choo, M.-Y.; Ong, H.C.; Lee, H.V.; Show, P.L.; Lin, Y.-C.; Juan, J.C. Efficient deoxygenation of triglycerides to hydrocarbon-biofuel over mesoporous $\mathrm{Al}_{2} \mathrm{O}_{3}-\mathrm{TiO}_{2}$ catalyst. Fuel Process Technol. 2019, 194, 106120. [CrossRef]

18. Oi, L.E.; Choo, M.-Y.; Lee, H.V.; Taufiq-Yap, Y.H.; Cheng, C.K.; Juan, J.C. Catalytic deoxygenation of triolein to green fuel over mesoporous $\mathrm{TiO}_{2}$ aided by in situ hydrogen production. Int. J. Hydrog. Energy 2020, 45, 11605-11614. [CrossRef]

19. Santillan-Jimenez, E.; Morgan, T.; Lacny, J.; Mohapatra, S.; Crocker, M. Catalytic deoxygenation of triglycerides and fatty acids to hydrocarbons over carbon-supported nickel. Fuel 2013, 103, 1010-1017. [CrossRef] 
20. Yang, L.; Carreon, M.A. Deoxygenation of Palmitic and Lauric Acids over Pt/ZIF-67 Membrane/Zeolite 5A Bead Catalysts. ACS Appl. Mater. Interfaces 2017, 9, 31993-32000. [CrossRef]

21. Zhang, J.; Zhao, C. Development of a Bimetallic Pd-Ni/HZSM-5 Catalyst for the Tandem Limonene Dehydrogenation and Fatty Acid Deoxygenation to Alkanes and Arenes for Use as Biojet Fuel. ACS Catal. 2016, 6, 4512-4525. [CrossRef]

22. Liu, Z.; Li, H.; Zeng, J.; Liu, M.; Zhang, Y.; Liu, Z. Influence of Fe/HZSM-5 catalyst on elemental distribution and product properties during hydrothermal liquefaction of Nannochloropsis sp. Algal Res. 2018, 35, 1-9. [CrossRef]

23. Yang, Z.; Liu, Y.; Liu, D.; Meng, X.; Liu, C. Hydroisomerization of n-octane over bimetallic Ni-Cu/SAPO-11 catalysts. Appl. Catal. A Gen. A 2017, 543, 274-282. [CrossRef]

24. De, S.; Zhang, J.; Luque, R.; Yan, N. Ni-based bimetallic heterogeneous catalysts for energy and environmental applications. Energy Environ. Sci. 2016, 9, 3314-3347. [CrossRef]

25. Li, T.; Cheng, J.; Huang, R.; Zhou, J.; Cen, K. Conversion of waste cooking oil to jet biofuel with nickel-based mesoporous zeolite Y catalyst. Bioresour. Technol. 2015, 197, 289-294. [CrossRef] [PubMed]

26. Lycourghiotis, S.; Kordouli, E.; Sygellou, L.; Bourikas, K.; Kordulis, C. Nickel catalysts supported on palygorskite for transformation of waste cooking oils into green diesel. Appl. Catal. B Environ. 2019, 259, 118059. [CrossRef]

27. Song, W.; Zhao, C.; Lercher, J.A. Importance of Size and Distribution of Ni Nanoparticles for the Hydrodeoxygenation of Microalgae Oil. Chem. Eur. J. 2013, 19, 9833-9842. [CrossRef]

28. Marei, N.N.; Nassar, N.N.; Vitale, G. The effect of the nanosize on surface properties of NiO nanoparticles for the adsorption of Quinolin-65. Phys. Chem. Chem. Phys. 2016, 18, 6839-6849. [CrossRef]

29. Cauqui, M.A.; Rodriguezizquierdo, J.M. Application of the Sol-Gel Methods to Catalyst Preparation. J. Non-Cryst. Solids 1992, 147, 724-738. [CrossRef]

30. Dong, X.; Ma, X.; Xu, H.; Ge, Q. Comparative study of silica-supported copper catalysts prepared by different methods: Formation and transition of copper phyllosilicate. Catal. Sci. Technol. 2016, 6, 4151-4158. [CrossRef]

31. Yan, P.; Mensah, J.; Adesina, A.; Kennedy, E.; Stockenhuber, M. Highly-dispersed Ni on BEA catalyst prepared by ion-exchange-deposition-precipitation for improved hydrodeoxygenation activity. Appl. Catal. B Environ. 2020, 267, 118690. [CrossRef]

32. Burattin, P.; Che, M.; Louis, C. Characterization of the Ni(II) Phase Formed on Silica Upon Deposition-Precipitation. J. Phys. Chem. B 1997, 101, 7060-7074. [CrossRef]

33. Asikin-Mijan, N.; Lee, H.V.; Juan, J.C.; Noorsaadah, A.R.; Taufiq-Yap, Y.H. Catalytic deoxygenation of triglycerides to green diesel over modified CaO-based catalysts. RSC Adv. 2017, 7, 46445-46460. [CrossRef]

34. Choo, M.-Y.; Oi, L.E.; Ling, T.C.; Ng, E.-P.; Lin, Y.-C.; Centi, G.; Juan, J.C. Deoxygenation of triolein to green diesel in the H2-free condition: Effect of transition metal oxide supported on zeolite Y. J. Anal. Appl. Pyrolysis 2020, 147, 104797. [CrossRef]

35. Zulkepli, S.; Juan, J.C.; Lee, H.V.; Rahman, N.S.A.; Show, P.L.; Ng, E.P. Modified mesoporous HMS supported $\mathrm{Ni}$ for deoxygenation of triolein into hydrocarbon-biofuel production. Energy Convers. Manag. 2018, 165, 495-508. [CrossRef]

36. Baharudin, K.B.; Taufiq-Yap, Y.H.; Hunns, J.; Isaacs, M.; Wilson, K.; Derawi, D. Mesoporous NiO/Al-SBA-15 catalysts for solvent-free deoxygenation of palm fatty acid distillate. Microporous Mesoporous Mater. 2019, 276, 13-22. [CrossRef]

37. Soghrati, E.; Ong, T.K.C.; Poh, C.K.; Kawi, S.; Borgna, A. Zeolite-supported nickel phyllosilicate catalyst for CO hydrogenolysis of cyclic ethers and polyols. Appl. Catal. B Environ. 2018, 235, 130-142. [CrossRef]

38. Li, W.; Zheng, J.; Luo, Y.; Da, Z. Effect of hierarchical porosity and phosphorus modification on the catalytic properties of zeolite Y. Appl. Surf. Sci. 2016, 382, 302-308. [CrossRef]

39. Choo, M.-Y.; Juan, J.C.; Oi, L.E.; Ling, T.C.; Ng, E.-P.; Rahman Noorsaadah, A.; Centi, G.; Lee, K.T. The role of nanosized zeolite $\mathrm{Y}$ in the H2-free catalytic deoxygenation of triolein. Catal. Sci. Technol. 2019, 9, 772-782. [CrossRef]

40. Zhang, Q.; Ming, W.; Ma, J.; Zhang, J.; Wang, P.; Li, R. De novo assembly of a mesoporous beta zeolite with intracrystalline channels and its catalytic performance for biodiesel production. J. Mater. Chem. A 2014, 2, 8712-8718. [CrossRef]

41. Jiao, W.Q.; Fu, W.H.; Liang, X.M.; Wang, Y.M.; He, M.-Y. Preparation of hierarchically structured Y zeolite with low Si/Al ratio and its applications in acetalization reactions. RSC Adv. 2014, 4, 58596-58607. [CrossRef] 
42. Zhang, Z.; Liu, B.; Liu, F.; Zhao, Y.; Xiao, T. Effect of nickel loading on the performance of nano- and micro-sized ZSM-5 catalysts for methanol to hydrocarbon conversion. Catal. Today 2018, 317, 21-28. [CrossRef]

43. Qiu, S.; Zhang, X.; Liu, Q.; Wang, T.; Zhang, Q.; Ma, L. A simple method to prepare highly active and dispersed Ni/MCM-41 catalysts by co-impregnation. Catal. Commun. 2013, 42, 73-78. [CrossRef]

44. Al-Ani, A.; Darton, R.J.; Sneddon, S.; Zholobenko, V. Nanostructured Zeolites: The Introduction of Intracrystalline Mesoporosity in Basic Faujasite-type Catalysts. ACS Appl. Nano Mater. 2018, 1, 310-318. [CrossRef]

45. Ng, E.-P.; Tat-Lun Ng, D.; Awala, H.; Wong, K.-L.; Mintova, S. Microwave synthesis of colloidal stable AlPO-5 nanocrystals with high water adsorption capacity and unique morphology. Mater. Lett. 2014, 132, 126-129. [CrossRef]

46. Awala, H.; Gilson, J.-P.; Retoux, R.; Boullay, P.; Goupil, J.-M.; Valtchev, V.; Mintova, S. Template-free nanosized faujasite-type zeolites. Nat. Mater. 2015, 14, 447-451. [CrossRef] [PubMed]

47. Cheng, J.; Zhang, Z.; Zhang, X.; Liu, J.; Zhou, J.; Cen, K. Sulfonated mesoporous Y zeolite with nickel to catalyze hydrocracking of microalgae biodiesel into jet fuel range hydrocarbons. Int. J. Hydrog. Energy 2019, 44, 1650-1658. [CrossRef]

48. Berenguer, A.; Bennett, J.A.; Hunns, J.; Moreno, I.; Coronado, J.M.; Lee, A.F.; Pizarro, P.; Wilson, K.; Serrano, D.P. Catalytic hydrodeoxygenation of m-cresol over Ni2P/hierarchical ZSM-5. Catal. Today 2018, 304, 72-79. [CrossRef]

49. Yung, M.M.; Starace, A.K.; Mukarakate, C.; Crow, A.M.; Leshnov, M.A.; Magrini, K.A. Biomass Catalytic Pyrolysis on Ni/ZSM-5: Effects of Nickel Pretreatment and Loading. Energy Fuels 2016, 30, 5259-5268. [CrossRef]

50. Romero Sarria, F.; Saussey, J.; Gallas, J.P.; Marie, O.; Daturi, M. In situ and operando IR study of adsorption sites for $\mathrm{NH}_{4}^{+}$active species in $\mathrm{NO}_{x}-\mathrm{SCR}$ via $\mathrm{NH}_{3}$ using a Y zeolite. In Studies in Surface Science and Catalysis; Čejka, J., Žilková, N., Nachtigall, P., Eds.; Elsevier: Amsterdam, The Netherlands, 2005; pp. 821-828.

51. Hermida, L.; Amani, H.; Saeidi, S.; Zuhairi Abdullah, A.; Rahman Mohamed, A. Selective acid-functionalized mesoporous silica catalyst for conversion of glycerol to monoglycerides: State of the art and future prospects. Rev. Chem. Eng. 2018, 34, 239. [CrossRef]

52. Morgan, T.; Grubb, D.; Santillan-Jimenez, E.; Crocker, M. Conversion of Triglycerides to Hydrocarbons Over Supported Metal Catalysts. Top. Catal. 2010, 53, 820-829. [CrossRef] 